\title{
Bicycle-spoke injuries of the foot and ankle: A prospective study
}

\author{
H.K. Gupta, ${ }^{1}$ R. Shrestha ${ }^{2}$ \\ ${ }^{1,2}$ Lecturer, Department Of Orthopaedics, College of Medical Sciences and Teaching Hospital, Bharatpur, \\ Nepal.
}

\section{ABSTRACT \\ Objective}

Bicycle spoke wheel injuries can be as simple as minor abrasions and lacerations even to amputation of toes and heel injuries. The purpose of this study was to assess the severity of soft tissue damage and skeletal injuries in such injuries.

\section{Methods}

This prospective observational study included all the cases with spoke wheel injuries presenting between October 2012 to September 2013 in the College of Medical Sciences and Teaching Hospital, Bharatpur. Demographic information was collected from each patient including age, sex, injured side, position at the time of injury, and characteristic of injury. The soft tissue injury was classified according to Oestern and Tscherne classification and managed accordingly.

\section{Results}

A total of 50 cases were included in the study with 29 males ( $58 \%$ ) and 21 females (42\% ). Their age ranged from 6 yrs to 12 yrs (mean 9 yrs.). The mean interval from injury to presentation in hospital was 5 hrs (range 1-22 hrs). Majority had injury to right ankle and foot. Fore foot and mid foot injuries were more common when the feet got entrapped in front wheel. 36 cases had sustained injury while riding as pillion on the back seat and their injury was on posterior ankle $(n=20)$ and posterolateral aspect of ankle and foot $(n=16)$. Majority of cases were of grade 0 and 1 injury. Two patients had grade 3 injury, one with great toe amputation another with partial heel avulsion and exposed tendoachilles. All cases were managed with wound care, tetanus prophylaxis and splintage of the foot.

\section{Conclusion}

In our study we found that these spoke wheel related injuries were more common in children and are important cause of temporary loss of daily activities. Although all injuries healed properly, risk of severe injuries like amputations and heel pad loss and tendoachilles transaction and fractures of foot and ankle still prevails where bicycle is a common mode of transportation.

Key-words: Bicycle spoke injuries, foot and ankle, soft tissue injuries. 
Journal of College of Medical Sciences-Nepal, 2013, Vol-9, No-4,

\section{INTRODUCTION}

Bicycles have been very popular mode of transport and owned by nearly all families in our part of the world. Many people can be seen riding bicycle along with extra passenger sitting on the bar joining handle and the seat, or the pillion, with feet dangling on either the sides of wheel or one side. In these conditions, the passengers are prone for having their feet and ankles being caught in between spokes of the wheel and the frame of bicycle resulting in various degrees of injuries. These injuries are termed as spoke wheel injuries. The injuries can be as simple minor abrasions, lacerations, crushing of toes and heel injuries etc. ${ }^{1,2,3}$ Children constitutes the largest group of victims of such injuries. ${ }^{4}$ The purpose of this study was to assess the severity of soft tissue damage and and skeletal injuries in such injuries.

\section{METHODS}

This study was conducted in College of Medical Sciences and Teaching Hospital, Bharatpur. The design of this study was a prospective observational study. All the cases with spoke wheel injuries presenting in emergency room or outpatient department between October 2012 to September 2013 were included in the study. Demographic information was collected from each patient including age, sex, injured side, position at the time of injury, and characteristic of injury. All the patients received lavage, cleaning of the wound and dressing of the wound. They also received tetanus prophylxis and antibiotics.

According to Oestern and Tscherne classification ${ }^{5}$, soft tissue injuries were classified. The classification was as follows:
Grade 0: Little or no soft-tissue injury.

Grade 1: Superficial abrasion or contusion/bruising

Grade 2: Deep, contaminated abrasion with local contusional damage to skin or muscle

Grade 3: Extensive skin contusion or crushing or muscle destruction or open fractures, damage to the vessels/nerves/tendons and /or exposure of bone.

Grade 0 injuries were treated with dressing of the wound, splintage with below knee plaster of POP slab and limb elevation. They were discharged from the hospital on the same day and followed up in out patient department. The splintage was advised for two weeks. Grade 1 injuries were treated with proper wound lavage with normal saline, dressing of the wound with betadine, splintage of the limb with POP slab and limb elevation. They were admitted in ward and limb re-evaluated the next day for swelling and status of the wound. Any sign of infection or discharge was noted. They also received oral cloxacillin for 7 days. Grade 2 injuries required more aggressive wound care, injectable antibiotic cefuroxime was given. Wound dressing done with betadine and limb splinted and admitted in ward. Below knee back splint was continued for 4 weeks. Grade 3 injuries required wound debridement under anaesthesia, repair of the tendons, any fracture fixations and below knee back splint of POP slab. They were admitted in ward with parenteral antibiotics, cefuroxime, gentamicin and metronidazole. The wound was inspected regularly and if required repeat debridement was done. After satisfactory healing ankle mobilization was advised, usually after 6 weeks. The duration of injuries to heal and residual disabilities were also noted on follow up. 
Bicycle-Spoke Injuries Of The Foot And Ankle: A Prospective Study

\section{RESULTS}

There were total of 50 cases of wheel-spoke injuries. The mean interval from injury to presentation in hospital was $5 \mathrm{hrs}$ ( range 1-22 hrs). There were 29 males ( $58 \%$ ) and 21 females $(42 \%)$. Their age ranged from 6 yrs to $12 \mathrm{yrs}$ ( mean 9 yrs.). 34 patients injured their right foot and 16 of them injured left foot. 14 cases were due to front wheel injuries and had injury to fore foot $(n=11)$ and mid foot $(n=3) .36$ cases had sustained injury while riding as pillion on the back seat and their injury was on posterior ankle $(n=20)$ and posterolateral aspect of ankle and foot $(n=16)$.

Out of 50 cases, 12, 26, 10 and 2 patients had sustained soft tissue injury of grades $0,1,2$ and 3 respectively. The patient with grade 2 and 3 required repeat debridement due to infection and tissue necrosis. Great toe amputation was seen in one case ( Figure 1) and partial heel avulsion was seen in one case with exposure of tendo-achilles ( Figure 2 ). The hospital stay of the patients with grade 1 ( Figure3) and 2 was 2-6 days ( mean 3 days). Grade 3 injuries took longer time to heal and hospital stay was prolonged. Their mean stay in hospital was 11 days( range 10-12 days). Almost all the patient with grade 0,1 and 2 had good healing with no residual pain or disabilities. The patient with great toe injury ended in amputation of the great toe and the patient with heel pad injury with exposed tendo-achilles healed over period of 14 days, slab was removed after total of 6 weeks. No patients required skin graft or secondary procedure for wound coverage.

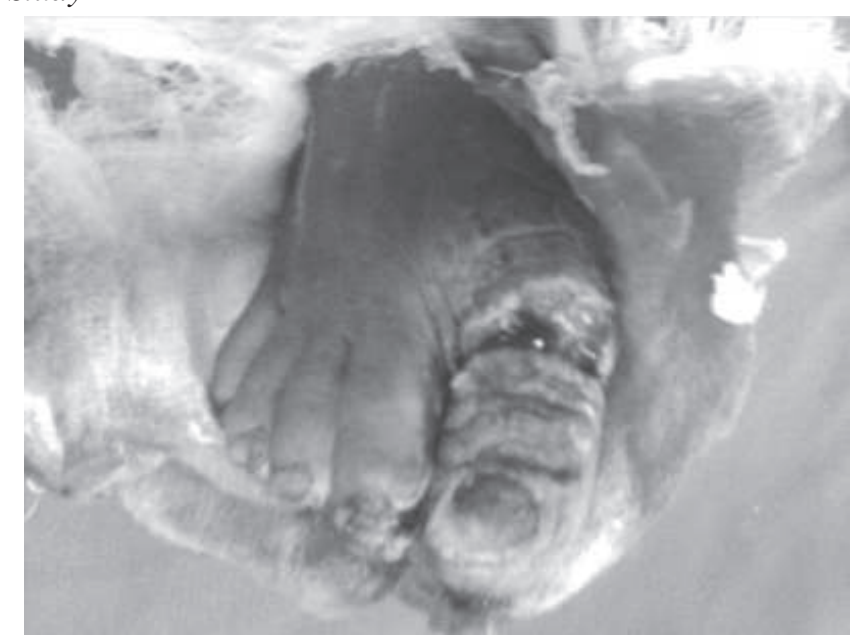

Figure 1 Amputation of great toe following spoke -wheel injury

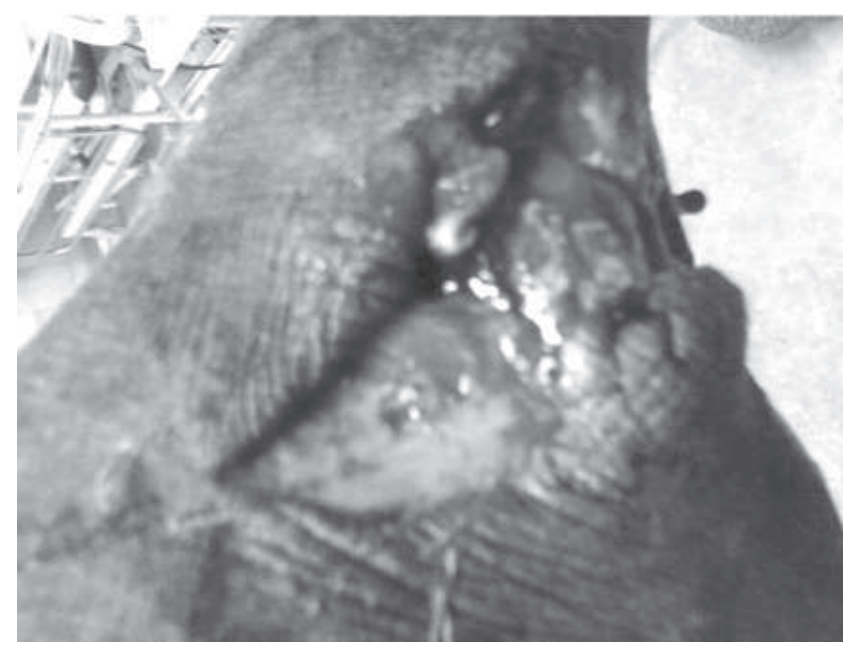

Figure 2 showing heel pad avulsion injury and exposed tendo-achilles

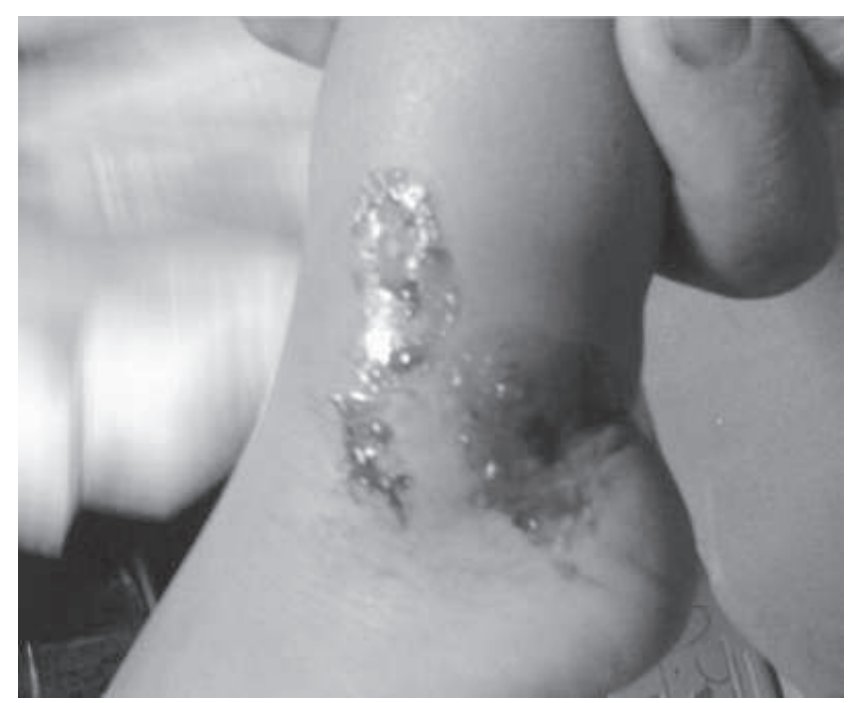

Figure 3 showing grade 1 spoke wheel injury. 
Journal of College of Medical Sciences-Nepal, 2013, Vol-9, No-4,

\section{DISCUSSION}

The majority of spoke-wheel injury occurred in the area of posterior aspect of ankle and posterolateral aspect. Most of them were minor injuries of grade 0 and 1. Severe injury to heel may lead to heel pad avulsion and often transaction of tendoachilles. ${ }^{2,6}$ Results of our study were consistent with them. In literatures, it has been shown that bicycle spoke injuries have resulted in severe heel pad injury, transaction of tendo-achilles and warranted the need for flap surgeries to cover the wounds. ${ }^{3,7}$ In a study by Mine et al, they have shown that spoke wheel injuries took longer time to heal and repeated debridement for severe injuries. ${ }^{8}$ Such injuries are often found to be deteriorating after $48 \mathrm{hrs}$ or later as the vascularity of soft tissue in this area is poor and internal degloving is common due to shearing force sustained to the skin. Hence it becomes mandatory to see the wound repeatedly for any change in status of the wound. An ankle foot orthosis or a back splint is also recommended as it helps in good healing and exercise to be performed. ${ }^{2}$ Various modifications in bicycle has been advised for preventing such injuries, like mesh cover, or plastic shield to bridge the gap between fork and horizontal upright of bicycle etc. ${ }^{9}$ Making the people aware of the mode of injury and preventive measures explained at the costumer level of bicycle could decrease the incidence of these injuries. ${ }^{10}$

\section{CONCLUSION}

Bicycle spoke-wheel injury is a potentially preventable accident. The injury sustained can be as simple as minor abrasion to even loss of toes or heel pad. The minor modification in bicycle so that foot doesn't get entrapped in the wheel, like a mess or plastic upright etc. can be taken into account. General people awareness regarding the injury, preventable measures, use of appropriate spoke guards, foot rests, children wearing proper shoes etc are the simplest measure to avoid the spokewheel injury.

\section{REFERENCES}

1. S. S. Sankhala, S. P. Gupta. Spoke-wheel injuries. Indian J Pediatr 1987;54:251-6.

2. A. Agarwal, M. Pruthi. Bicycle-spoke injuries of the foot in children. Journal of Orthopaedic Surgery 2010;18(3):338-41.

3. H. Xiu, F. Chong, J. Wai, et al. Treatment of spoke heel injuries in children. Ke Za Zhi 2009;23(10):1180-2.

4. A. Venema, S. Hag. Bicycle spoke entrapment in children. Injury Surveillance Exchange (CISE) 1999;2:5-6.

5. H. J. Oestern, H. Tscherne. Pathophysiology and classification of soft issue injuries associated with fractures. In: Tscherne H,editor. Fractures with soft tissues injuries. New York: Springer-Verlag;1984:1-9.

6. M. J. Segers, D. Wink, G. J. Clevers.. Bicyclespoke injuries: a prospective study. Injury 1997; 28(4):267-9.

7. M. P. Suri, N. R. Naik, S.C. Raibagkar, et al. Heel flap injuries in spoke wheel accidents. Injury 2007;38:619-24.

8. R. Mine, M. Fukui, G. Nishimura. Bicycle spoke injuries in the lower extremity. Plast Reconstr Surg. 2000;106(7):1501-6.

9. L. G. D’Souza, D. E. Hynes, F. McManus, et $a l$. The bicycle spoke injury: an avoidable accident? Foot Ankle Int. 1996;17(3):170-3.

10. J. A. Waller. Bicycle ownership, use, and injury patterns among elementary school children. Injury Prevention 1995;1: 256-61 